\title{
Face Cover: It is Time to upgrade our Masks
}

\section{Omkar Gijare}

\author{
MIT Academy of Engineering, Pune, India
}

Received: 05 Sept 2020; Received in revised form: 11 Nov 2020; Accepted: 21 Nov 2020; Available online: 07 Dec 2020 (C)2020 The Author(s). Published by Infogain Publication. This is an open access article under the CC BY license (https://creativecommons.org/licenses/by/4.0/).

\begin{abstract}
The planet Earth is currently facing one of its most critical crises over the history in form of COVID-19 Pandemic. Around the globe, almost every nation is penetrated by Coronavirus and the number of patients is increasing day by day. Along with time, the lockdowns are going on in each nation and their durations are not in condition of limiting. In education and various other sectors, it is being advised to run activities on digital platform but there are limitations on this platform regarding its capacity and its reach. In order to resume classes in schools and other educational institutes, (whenever the situation will permit this) the boundaries of social distancing are going to be very difficult to be maintained. The face cover seems to be one of the solutions for such situations. Only function of this face cover is to avoid direct touch of hands to the face strictly at all conditions. At the same time, it will contain the respiratory particulates of the wearer inside so that if someone is infected, the outbreak will be avoided. This face cover is capable of covering wearer's hair, mouth, nose and eyes and hence, it provides extensive safety to person from infection hazards. It is also equipped with the provision near mouth for opening so that the food and beverage consumption can be easily performed without removing the whole cover. Thus, the probability of infection can be reduced with such extensive protection and the world can proceed towards unlocking the environment.
\end{abstract}

Keywords-COVID-19, Coronavirus, Face mask, Lockdown, Social Distancing.

\section{INTRODUCTION}

As the COVID-19 situations are moving forward, the number of patients is rising exponentially and it is getting crucial to control the spread of Coronavirus. Worldwide healthcare systems are busy in providing care to infected people and their capacity is constraining them to take efforts towards controlling the spread of the virus. Community-wide mask wearing may contribute to the control of COVID-19 by reducing the amount of emission of infected saliva and respiratory droplets from individuals with subclinical or mild COVID-19 (Cheng V. C., Wong S., Chuang V., Yung-Chun So S., Chen J. H., Sridhar S., Kai-Wang To K., Chan J. F., Hung I. F., Ho P. \& Yuen K, 2020). Hence each and every nation's population is trying to control the spread by wearing the masks which cover mouth and nose but apparently, the spread is not being restricted by this measure in expected margin. Due to this, there is reluctance to wear mask in various nations and different reasons are given to avoid wearing the mask. Such reasons vary from masks complement the spread to wearing a mask is somewhat symbolic. Wearing a mask is not an act of selfishness and should be promoted as an act of solidarity. Hence using masks has to be obligated throughout the world. Apart from masks, people are using hand sanitizers, washing their hands frequently, and still the rise in number of patients observed is exponential. Physical distancing of at least $1 \mathrm{~m}$ is strongly associated with protection, but distances of up to $2 \mathrm{~m}$ might be more effective (Chu D. K., Akl E. A., Duda S., Solo K., Yaacoub S. \& Schünemann H. J, 2020). Considering all these factors, the opening of educational institutes cannot happen in the near future. On the other hand, educational institutes are about to lose patience and are waiting to obtain the permits to start the classes as the flow of teaching will be hampered if the classes delay. Though, it will be extremely hazardous to restart classes until the situation is not under control. Because social distancing is not at all going to be maintained once the educational institutes start functioning. Students will be exposed to the threat of infection which will result in immeasurable loss which cannot be imagined. To overcome such situation, schools and colleges are planning to divide the classes and increase the daily periods so as to achieve social 
distancing. Online classes are the new measure preferred nowadays by a variety of colleges.

As it is made clear by WHO, current evidence suggests that COVID-19 spreads between people through direct, indirect (through contaminated objects or surfaces), or close contact with infected people via mouth and nose secretions. These include saliva, respiratory secretions or secretion droplets. In other words, there are one of the two possibilities of a healthy person getting infected:

1. If infected person's respiratory particulates are inhaled by healthy person.

2. If landed respiratory particulates reach healthy person's hands and then to the face.

The masks currently being used overcome first possibility completely i.e. they contain respiratory particulates of every person and hence they avoid further transmission of the virus. The masks are to be washed and the hands are to be sanitized or washed frequently in order to achieve full effect over spread of the virus. As not every single person is following these measures, such rise of patients is observed. On the other hand, masks are not at all effective over the restrictions of touching the face frequently and naturally, people tend to touch their faces and hair for various reasons including itching. Hence, it is important to completely restrict the touching of face in order to avoid more infections. As the number of affected persons is rising day by day, the virus is predicted to mutate while accommodating human immunity. Hence it is very much crucial to stop the spread of Coronavirus is order to contain its widespread effects with respect to time horizon.

\section{METHODOLOGY}

A face cover made up of thick fabric can provide the solution to above mentioned problem. This cover will not only contain the respiratory particulates, but it will also avoid the touching to face completely. The cover is equipped with transparent yet thick plastics/rubber in position of eyes for the provision of seeing. This cover is locked at the back of the head using Velcro tapes or push buttons and this cover will be locked at all times when a person will be outside. This cover also has a provision in front for opening to allow food consumption but that will also be sealed by Velcro tapes or buttons at any other point of time. As it is obvious that a person will not eat without washing his hands carefully, the opening of this cover for that short duration of time will be safe. Even at the time of opening of this cover for consumption of food, its sanitization can be done externally so as to kill externally landed virus before touching the cover. Also, it will be advised to wash this cover every day so as to avoid infection even if the virus is landed on this cover from outside.

It is understandable that the cover is very much unconventional to use \& a design such as this has never come up while fighting the viral infections \& hence the rooting of this concept in the market will be quite unorthodox but in order to get all-around protection, there is no other alternative in vision in near future. The anxiety is increasing on one side whereas the social-distancing is being vital while stopping the spread $\&$ thus in order to be completely sure that in any case, the infection is avoided, the use of this cover is inevitable in near future. It can be also be taken as a social responsibility or initiative while rooting this cover into daily usage as the comfort \& safety in associated with this cover has no comparison with the masks currently being used. One more important aspect of this cover is that people nowadays do not use masks as a compulsion which is also resulting into more \& more infections but with the use of this cover, there are no escapes from fully covering the important areas. This cover either is wore completely or it is not, there is no other way to it.
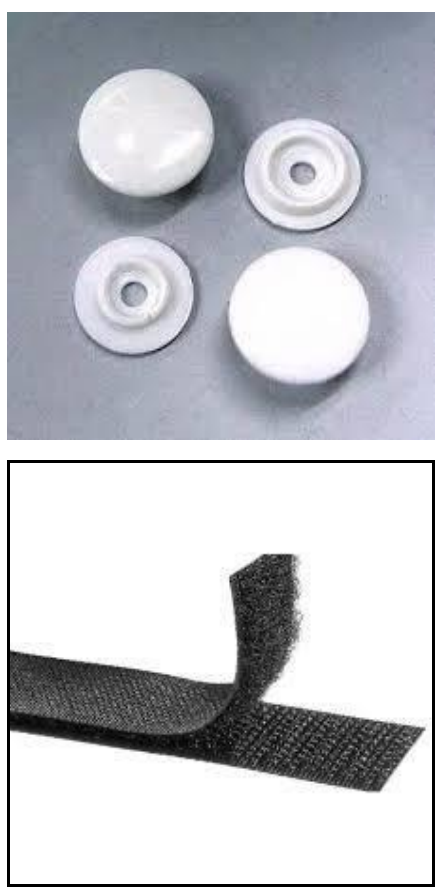

Fig.1: Push Buttons and Velcro tape 

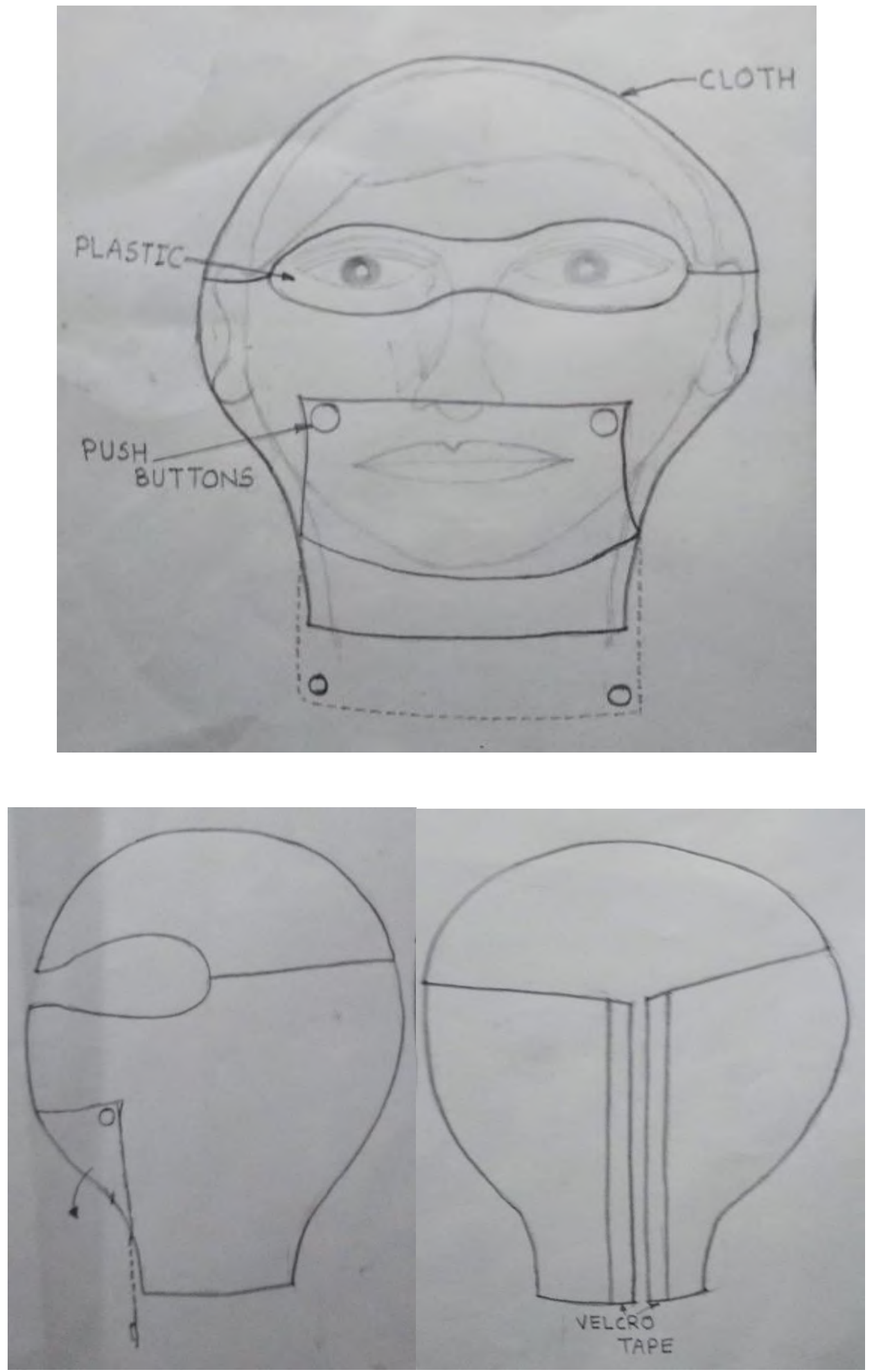

Fig.2: Face Cover

Procedure to use Face Cover:

1. While going outside, wear the face cover and lock up with the Velcro tapes.

2. As it will cover the whole face and head, touching at any point of time won't be a threat of infection.
3. Whenever the face cover is to be removed, the outer surface has to be sanitized thoroughly in order to avoid infection. There are high chances of the virus lingering on the outer surface. 
4. At the time of food or beverage consumption, the provision at front should be opened but it again has to be carefully sanitized before opening.

5. Strictly after each day, this cover should be washed gently with sanitization so as to completely avoid the contact with Coronavirus.

In such manner, the face cover provides a solution over the problem of increasing positive cases even after the use of masks. Nowadays various face shields are in the market which are made up of plastic (ABS) and they cover the

Table 1: Comparison of Face Cover with available alternatives

\begin{tabular}{|c|c|c|c|c|}
\hline Parameter & $\begin{array}{l}\text { Face } \\
\text { mask }\end{array}$ & $\begin{array}{l}\text { Face } \\
\text { shield }\end{array}$ & $\begin{array}{l}\text { Face shield }+ \text { Face mask }+ \\
\text { Cotton cap }\end{array}$ & $\begin{array}{l}\text { Face } \\
\text { Cover }\end{array}$ \\
\hline Protecting mouth, nose & $\sqrt{ }$ & $\sqrt{ }$ & $\sqrt{ }$ & $\sqrt{ }$ \\
\hline Protecting eyes & $\times$ & $\sqrt{ }$ & $\sqrt{ }$ & $\sqrt{ }$ \\
\hline Containing the virus & $\sqrt{ }$ & $\times$ & $\sqrt{ }$ & $\sqrt{ }$ \\
\hline Avoiding touch to any part of face, hair & $x$ & $x$ & $\sqrt{ }$ & $\sqrt{ }$ \\
\hline Avoiding inhalation of droplets (Fomites) & $\sqrt{1}$ & $\sqrt{ }$ & $\sqrt{ }$ & $\sqrt{ }$ \\
\hline Protecting Hair & $x$ & $x$ & $\sqrt{ }$ & $\sqrt{ }$ \\
\hline $\begin{array}{l}\text { Provision to allow food and beverage } \\
\text { consumption without removal }\end{array}$ & $\times$ & $x$ & $x$ & $\sqrt{ }$ \\
\hline
\end{tabular}

Thus, it can be clearly observed that the face cover can provide overall protection to the face, hair and it can avoid the infection to a greater extent relatively. This cover has to be cleansed by sanitizer every single day, similar to any other mask or equipment under use. At the time of lunch as well, this cover should be sprayed using sanitizer externally before opening the provision provided for eating. One of major perks of this cover is it is washable and hence reusable. Only care is to be taken while washing that the push buttons are to be handled gently.

\section{CONCLUSION}

The face cover is capable of avoiding any kind of touch to face, mouth, nose, eyes and hair as it covers all of these organs all the time. It discontinues the travel of Coronavirus from hands to the face and thus provides protection with consistency. It can be used after trials to reopen educational institutes and all the other firms as it is capable of containing the spread of virus. If this cover is used with all precautions of timely sanitization, social distancing upto $2 \mathrm{~m}$ can be waived of by a small extent and this will emancipate the world from constraints of lockdowns. Regular function of various organizations can revert due to decrement in spread of Coronavirus and this face from front. But the problem with such shields is they are stiff and even after using them, the user is not restricted from touching his face or hair. Landing the virus over hair is also one of the causes of infection and hence, covering of head is equally important which is not achieved by the face shield. Overall comparison of face cover and various PPEs currently available is illustrated in table 1. can be achieved only through explicit testing of this test cover.

\section{REFERENCES}

[1] Cheng V. C., Wong S., Chuang V., Yung-Chun So S., Chen J. H., Sridhar S., Kai-Wang To K., Chan J. F., Hung I. F., Ho P., Yuen K. (2020). The role of community-wide wearing of face mask for control of coronavirus disease 2019 (COVID-19) epidemic due to SARS-CoV-2. Journal of Infection, Journal of Infection Vol. 81, pp. 107-114

[2] Official website of WHO. Retrieved 14/7/2020 from https://www.who.int/emergencies/diseases/novelcoronaviru $\underline{\text { s2019/questionandanswers-hub/q-a-detail/q-a-how-is- }}$ covid-19-transmitted

[3] Chu D. K., Akl E. A., Duda S., Solo K., Yaacoub S., Schünemann H. J. (2020). Physical distancing, face masks, and eye protection to prevent person-to-person transmission of SARS-CoV-2 and COVID-19: a systematic review and meta-analysis, https://doi.org/10.1016/S01406736(20)31142-9

[4] European Centre for Disease Prevention and Control (2020). Technical Report on Using face masks in the community Reducing COVID-19 transmission from potentially asymptomatic or pre-symptomatic people through the use of face masks. 